NBER WORKING PAPER SERIES

\title{
GOOD RANKINGS ARE BAD: WHY RELIABLE RANKINGS CAN HURT CONSUMERS
}

\author{
Laurent Bouton \\ Georg Kirchsteiger \\ Working Paper 21083 \\ http://www.nber.org/papers/w21083
NATIONAL BUREAU OF ECONOMIC RESEARCH
1050 Massachusetts Avenue
Cambridge, MA 02138 \\ April 2015
}

We are grateful to Elena Arias Ortiz, Micael Castanheira, Thomas Gall, Alessandro Gavazza, Victor Ginsburgh, Alessandro Lizzeri, and Andy Newman for insightful comments. We also benefitted from the comments of the audiences at BU, ECARES, Université de Lausanne, and at the conference on Gaming Incentive Systems in Bonn. All remaining errors are ours. The views expressed herein are those of the authors and do not necessarily reflect the views of the National Bureau of Economic Research.

NBER working papers are circulated for discussion and comment purposes. They have not been peerreviewed or been subject to the review by the NBER Board of Directors that accompanies official NBER publications.

(C) 2015 by Laurent Bouton and Georg Kirchsteiger. All rights reserved. Short sections of text, not to exceed two paragraphs, may be quoted without explicit permission provided that full credit, including (C) notice, is given to the source. 
Good Rankings Are Bad: Why Reliable Rankings Can Hurt Consumers

Laurent Bouton and Georg Kirchsteiger

NBER Working Paper No. 21083

April 2015

JEL No. D8,L15

\section{ABSTRACT}

Rankings have become increasingly popular on various markets, e.g. the market for study programs. We analyze their welfare implications. Consumers have to choose between two goods of unknown quality with exogenous presence or absence of an unbiased informative ranking. The existence of the ranking might affect the welfare of all consumers negatively. With rigid prices, the ranking induced change in demand can be detrimental to all consumers in markets featuring rationing or consumption externalities. With perfectly flexible prices, the ranking might increase firms' market power, and hence lead to losses for all consumers even in the absence of rationing and consumption externalities.

Laurent Bouton

Georgetown University

Department of Economics

37 th \& O Streets, NW

Washington,DC 20057

and NBER

boutonllj@gmail.com

Georg Kirchsteiger

ECARES, Université Libre de Bruxelles

Av. Roosevelt 50, CP 114/04

1050 Brussels

Belgium

gkirchst@ulb.ac.be 


\section{Introduction}

You are a frequent patron of a little-known restaurant. While you and the intimate gathering of fellow patrons enjoy good food, good service and a quiet atmosphere, the rest of the dining-out crowd, who choose other establishments, suffer mediocre food, indifferent service and noise. After a few blissful months, disaster strikes: your restaurant is reviewed in the local paper. The next time you visit, there is a line out the door. When at last you are seated at one of the extra tables that has been crammed in next to the restroom, the noise is insufferable, the overwhelmed waitstaff ignores you, and the food, when it finally arrives, is overcooked. On top of everything, prices have skyrocketed. Obviously you are worse off, having lost your "private" restaurant. But what about all the new patrons? After all, they left mediocrity behind, so surely they are better off than they were. Or are they?

In the last twenty years, rankings ${ }^{1}$ have become increasingly popular. While restaurants and hotels have been ranked for a long time (the first red Michelin guide appeared more than 100 years ago), rankings are now available for education institutions and programs (see e.g. US News and World Report's rankings of colleges and graduate schools, and the Financial Times' ranking of MBA programs), wine (e.g. the famous Parker guide), health insurances and health care providers (e.g. The National Committee for Quality Assurance's plan ratings). Furthermore, the internet provides rankings based on consumers evaluation, e.g. in the fields of gastronomy (Yelp.com), medical services, and cars (cars.com).

Most of the scientific research on rankings investigates their quality. ${ }^{2}$ In the context of academic economic research, ranking methods have been discussed by Kalaitzidakis et al. (2010), and Palacios-Huerta and Volij (2004) among others. There has been quite some concern that firms or other interested parties might manipulate the outcome of rankings (Dranove et al. 2003 for a case with consumer-input technology, Glazer and McGuire 2006 and Glazer et al. 2008 for multi-tasking issues, and Sorensen 2006 for effects on products diversity) and that this might be harmful for consumers. But little research has been

\footnotetext{
${ }^{1}$ In this paper, we use the word "ranking" in a very general sense. It encompasses any type of information about the quality of a given set of goods.

${ }^{2}$ See Dranove and Jin (2010) for a thorough review of the literature.
} 
conducted on the welfare impact of (correct) rankings (see below for some exceptions). The literature investigating the quality of rankings seems to be based on the implicit assumption that rankings, if correct, are good for welfare - more information should not hurt. This view is well summarized by Dranove and Jin (2010, p. 952): "One of the purported benefits of disclosure is that it facilitates better matches between consumers and products. Consumers may migrate towards higher quality sellers ('vertical sorting') or to sellers whose product characteristics best meet their idiosyncratic needs ('horizontal sorting.') Both vertical and horizontal sorting effect could substantially increase welfare even if product attributes remain unchanged."

If rankings were only used in individual decision problems, better information could indeed never hurt. However, in many "real-world" markets where rankings play a role, agents' choices are not adequately described as individual decision problems. Consider education programs. Students learn from their peers, and the network generated at a school is crucial for future professional success. Or consider restaurants: for many customers the value of a dinner is influenced by the identity of the other customers of the restaurant. In other words, these markets are characterized by consumption externalities. Furthermore, in some markets, prices are not perfectly flexible, leading to rationing. A prototypical example are again education programs, where good programs are oversubscribed and hence schools choose among applicants. Finally, in markets with fully flexible prices and without externalities, firms' price-setting behavior is influenced by the demand, and hence agents' choices are not adequately described as individual decision problems.

To analyze the impact of rankings generated by rationing, externalities, and market power, we use a stylized framework with two goods that differ in quality. It is not known ex ante which good is the better one. We compare situations with and without rankings. Since we do not deal with the question of a ranking's credibility, we assume that the ranking - if it exists - always reflects the true qualities. There are two types of consumers who differ in terms of appreciation for the goods, and in terms of the externalities they inflict on other consumers of the same good. Importantly, consumers take the ranking into account when choosing which good to consume. ${ }^{3}$ For fixed prices, we show that,

\footnotetext{
${ }^{3}$ The empirical literature shows that consumers' choices are influenced by information on product quality (see e.g. Jin and Leslie 2003, Pope 2009, Luca 2011, and Luca and Smith 2012).
} 
without consumption externalities and without capacity constraints, the existence of a ranking makes all types of consumers weakly better off and, for some parameters, leads to a strict Pareto improvement. By contrast, in the presence of externalities or capacity constraints, a ranking may lead to a Pareto deterioration - the expected utility of both types of consumers is strictly lower with than without the ranking. These harmful effects are more likely the less the rationing procedure selects of one type and the more important the quality of the good and the consumption externalities are.

If one allows for flexible prices, the existence of a ranking might hurt consumers even in markets without capacity constraints and consumption externalities. Flexible prices allow for an additional reason why rankings can hurt consumers: the ranking might increase the market power of firms. This detrimental effect is more likely the more important the quality differences between the goods are. In other words, the more consumers care about the quality difference reflected by the ranking, the more likely it is that all consumers suffer from the presence of the ranking.

Our analysis assumes that the quality of goods is given, i.e. firms cannot choose the quality of their goods. While this assumption is clearly a simplification, it is quite plausible for many goods. The competence of a particular medical doctor is to a large extent determined by his education and his talent, it is not at his discretion. The quality of wine reflects soil and climate, factors difficult if not impossible to change. Developing new cars is a long and very costly process. Changing the quality of a large institution like a university or a health care provider takes many years, even decades. The quality of other goods like restaurant food or health insurance can be changed more easily. Due to tractability reasons, we have not analyzed the impact of rankings on markets when the quality of the goods can be easily changed. But we suspect that, in the case of flexible qualities, the effect of rankings would be similar to that in the case of flexible prices. With flexible qualities, rankings would allow for more product differentiation and hence increase firms' market power. This in turn could be detrimental for all consumers.

It has been argued in the literature that (correct) rankings can hurt some consumers. Yet, as far as we know, our paper is the first showing that rankings can hurt all consumers. Gavazza and Lizzeri (2007) analyze the impact of rationing on the overall surplus of con- 
sumers. In particular, they show that more information about school quality reduces overall surplus when slots for oversubscribed schools are distributed randomly. Unlike our paper, no form of Pareto-efficiency with respect to the different types of students is considered, and the impact of consumer's externalities and flexible prices is not analyzed. ${ }^{4}$ Morris and Shin (2002) analyze the impact of public information in a setting in which (i) there is strategic complementary in agents' actions, and (ii) agents hold private information. They show that increased precision of public information may be harmful. The reason is that because of coordination motivations, agents disregard their private (and more precise) information, and are thereby more likely to make "mistakes". Though also driven by the coordination effect of public information, our results are fundamentally different. First, in our setting, agents do not have private information to disregard. Second, in our paper, public information has a coordination effect because it reveals that one product is better than the other, not because it indirectly reveals what other agents are going to do. Both in the rationing and in the consumption externality cases, the coordination effect of public information leads to collateral damages that exist because of the strategic complementaries in consumers' actions. In the context of flexible prices, Anderson and Renault (2000) show that uninformed consumers can exert a positive externality on others. Thus, information acquisition by consumers might be socially excessive. By contrast, in our model, all consumers hold the same information about a good's quality. Finally, Anderson and Renault (2009) also show that better information might decrease consumer surplus. But this result is derived within a matching framework, where the information refers to horizontal aspects of the good and not to its quality.

The paper is organized as follows. Section 2 lays out the setup. Section 3 analyzes the effect of rankings under the assumption that prices are given and equal to marginal costs. We identify two features of markets that may make rankings undesirable: capacity constraints and consumption externalities. Section 4 relaxes the assumption of exogenous prices. It shows that rankings may affect firms' market power through an increase in product differentiation. Rankings thus affect prices and may ultimately diminish consumers' welfare. Section 5 concludes. All proofs are relegated to the Appendix.

\footnotetext{
${ }^{4}$ They actually suggest that such a negative effect does not hold when prices are flexible.
} 


\section{Setup}

We consider a market with two goods of unknown quality. Each consumer acquires one unit of one of the goods. If a ranking exists, it provides perfect information about the goods' quality.

Goods. There are two goods ${ }^{5}, m \in M=\{e, c\}$. Both goods are produced by the same constant returns to scale technology with marginal costs that we normalize to be zero. The price for good $m$ in ranking situation $\rho$ is $f_{m}^{\rho}$ ( $\rho$ is defined more precisely below). In Section 3, prices are fixed with $f_{e}^{\rho}=f_{e}>f_{c}^{\rho}=f_{c} \forall \rho$, whereas in Section 4, firms compete in prices, and the prices chosen by the firms depend on the ranking situation.

One of the two goods is of high quality, the other one of low quality. With a commonly known ex ante probability $\lambda^{0}>0.5$, good $e$ has the higher quality. Quality is measured such that it is proportional to the direct utility gained from consuming the good.

Ranking. If a ranking exists, it is published before consumers decide which good to request. It resolves the uncertainty about the quality of the good. ${ }^{6}$ There are three possible ranking situations, and we use superscript $\rho \in\{0,1,2\}$ to identify them: $\rho=0$ refers to a situation without ranking, in which the consumers' beliefs are given by $\lambda^{0}$; $\rho=1$ when good $e$ is better and ranked higher (confirmative ranking), and hence $\lambda^{1}=1$; $\rho=2$ when good $c$ is better and ranked higher (surprise ranking), with $\lambda^{2}=0$.

Consumers. There is a continuum $[0,2]$ of consumers, each one acquiring one unit of one good. There are two types of consumers, $t \in T=\{1,2\}$. The consumers' population is composed of equal fractions of these two types. We denote by $b_{t}^{h}\left(b_{t}^{l}\right)$ the evaluation by a type $t$ consumer of the quality of a good when this quality is high (low), with $b_{t}^{h}>b_{t}^{l}$. Denote by $\Delta b_{t}=b_{t}^{h}-b_{t}^{l}$ the relative gain of consumer type $t$ from consuming the high quality good. We name the types such that $\Delta b_{1}>\Delta b_{2}$. The overall utility of a consumers depends on the quality of the good consumed, on the price, on possible capacity constraints and the resulting selection mechanisms (see section 3.1), on externalities (see section 3.2), and on idiosyncratic preferences of the individual consumers for the different

\footnotetext{
${ }^{5}$ The two goods should be viewed as close substitutes, e.g. dinner in two different restaurants, study programs in the same field at two different universities, etc.

${ }^{6}$ In a previous version of the paper, we allowed the ranking to be imperfect. All of the main results can be derived within such a framework, but the analysis is considerably more complicated.
} 
goods (see Section 4). The utility functions are specified in the respective sections.

All consumers decide simultaneously which good they request to buy. The set of pure strategies of consumer $i$ is given by: $s_{i}=\left(s_{i}^{0}, s_{i}^{1}, s_{i}^{2}\right) \in\{e, c\}^{3}$, where $s_{i}^{\rho}=m$ means that consumer $i$ wants to buy good $m$ in ranking situation $\rho$. We denote by $x_{1}^{\rho}\left(x_{2}^{\rho}\right)$ the fraction of type 1 (2) consumers wanting to buy good $e$ in situation $\rho$.

Welfare criteria: To investigate the welfare impact of a ranking, we compare the equilibrium utilities of both types of agents with and without the ranking. This Pareto comparison might refer to the agents' expected utilities before the outcome of the ranking is known. Or it refers to the agents' utilities for both ranking outcomes. Denote by $U_{t}^{\rho}$ the utility a type $t$ consumer $i$ can expect in ranking situation $\rho .^{7}$ We use the following efficiency notions:

Definition 1 i) The absence of the ranking ex ante dominates its presence if for $t \in$ $\{1,2\}$ :

$$
U_{t}^{0}>\lambda^{0} U_{t}^{1}+\left(1-\lambda^{0}\right) U_{t}^{2}
$$

ii) The presence of the ranking ex ante dominates its absence if for $t \in\{1,2\}$ :

$$
U_{t}^{0}<\lambda^{0} U_{t}^{1}+\left(1-\lambda^{0}\right) U_{t}^{2}
$$

iii) The absence of the ranking ex post dominates its presence if for $t \in\{1,2\}$ :

$$
U_{t}^{0}>\max \left(U_{t}^{1}, U_{t}^{2}\right)
$$

iv) The presence of the ranking ex post dominates its absence if for $t \in\{1,2\}$ :

$$
U_{t}^{0}<\min \left(U_{t}^{1}, U_{t}^{2}\right)
$$

Obviously, ex post dominance implies ex ante dominance.

\footnotetext{
${ }^{7}$ With consumption externalities (Section 3.2) the equilibrium, and hence $U_{t}^{\rho}$, need not be unique. But all the welfare results of Section 3.2 refer to parameter constellations where the equilibrium is unique. To save on notation, we do not take explicitly the potential multiplity of equilibria into account when defining the welfare criteria.
} 


\section{Fixed Prices: Capacity Constraints and Externalities}

In this section, we study the case where prices are fixed, with good $e$ being more expensive than good $c$ (i.e. $f_{e}>f_{c}$ ). We denote the price difference by $\Delta f=f_{e}-f_{c}$.

Without capacity constraints and externalities, the consumers face an individual decision problem. The expected utilities from choosing $s_{i}^{\rho}=e\left(s_{i}^{\rho}=c\right)$ are given by

$$
\begin{aligned}
& u_{t}^{\rho}(e)=\lambda^{\rho} b_{t}^{h}+\left(1-\lambda^{\rho}\right) b_{t}^{l}-f_{e}, \\
& u_{t}^{\rho}(c)=\lambda^{\rho} b_{t}^{l}+\left(1-\lambda^{\rho}\right) b_{t}^{h}-f_{c} .
\end{aligned}
$$

Hence, $U_{t}^{\rho}=u_{t}^{\rho}(e)$ iff $\left(2 \lambda^{\rho}-1\right) \Delta b_{t}>\Delta f$. Otherwise $U_{t}^{\rho}=u_{t}^{\rho}(c)$. Using this, we obtain the following result: ${ }^{8}$

Proposition 1 For all types of consumers, $t \in\{1,2\}$, the presence of the ranking ex ante dominates its absence. Moreover, there is an open set of parameter values such the presence of the ranking ex post dominates its absence.

Proof. See Appendix A1.

But in the presence of either capacity constraints or consumption externalities, the existence of a rankings can lead to an ex ante Pareto deterioration. We first turn to the analysis of capacity constraints.

\subsection{The Welfare Implications of Capacity Constraints}

For simplicity, we assume that the supply of both goods is the same and denoted by $z \in(1,2) \cdot{ }^{9}$ This guarantees that, together, both producers can serve the whole market. Any demand for a particular good below $z$ is served. But the provider of a particular good has to select among its potential consumers whenever more than $z$ consumers want to buy his good. We assume that those consumers who cannot buy their preferred good are willing to buy the other good - it is always better to consume one of the two goods rather than none of them. Formally, we denote by $n_{t}\left(x_{1}, x_{2}\right)$ the mass of consumers of

\footnotetext{
${ }^{8}$ For all results in this paper, we focus on generic parameter values.

${ }^{9}$ Allowing for different supplies would considerably complicate the notation without changing any of our results.
} 
type $t$ who get good $e$ when $x_{1}$ type 1 and $x_{2}$ type 2 consumer want good $e$. This function is assumed to be continuous. For simplicity, we assume that both types of producers use the same selection process. This implies that $n_{t}\left(x_{1}, x_{2}\right)=1-n_{t}\left(1-x_{1}, 1-x_{2}\right)$.

In case of rationing, we have to distinguish between rationing schemes that perfectly discriminate in favor of one type, and those that do not discriminate perfectly (or do not discriminate at all).

Definition 2 (Perfect Discrimination) A rationing scheme discriminates perfectly in favor of type $\hat{t}$ if, for all $\left(x_{1}, x_{2}\right) \in[0,1]^{2}$, all type $\hat{t}$ customers who want the good get it, i.e. $n_{\hat{t}}\left(x_{1}, x_{2}\right)=x_{\hat{t}}$.

Definition 3 (Imperfect Discrimination) A rationing scheme discriminates imperfectly if, for all $t$ and for all $\left(x_{1}, x_{2}\right) \in[0,1]^{2}$ with $x_{1}+x_{2}>z$, the mass of selected type $t$ customers, $n_{t}\left(x_{1}, x_{2}\right)$, is strictly increasing in $x_{t}$ and strictly decreasing in $x_{t^{\prime}}$.

With perfect discrimination all customers of the favored type are served, even if the good is rationed. But with imperfect discrimination, this is not the case. The reason might be imperfect observability of the type of a customer (e.g. in case of admission to university programs) or a rationing scheme that does not take the type into account at all (e.g. rationing on a first come-first serve basis).

For the welfare analysis, we will not take into account which of the individual agents consumes which good. Rather, we will look at the average payoff each type can expect in equilibrium before the rationing scheme selects the actual customers (and before the true quality is revealed if the ranking is absent). Recall that the mass of both types of consumers is one. Hence, $n_{t}$ is the portion of type $t$ customers consuming good $t$. Denote by $x^{\rho *}=\left(x_{1}^{\rho *}, x_{2}^{\rho *}\right), \rho \in\{0,1,2\}$, the equilibrium. The average equilibrium payoff of a consumer of type $t$ is:

$$
U_{t}^{\rho}=n_{t}\left(x_{1}^{\rho *}, x_{2}^{\rho *}\right)\left[\lambda^{\rho} b_{t}^{h}+\left(1-\lambda^{\rho}\right) b_{t}^{l}-f_{e}\right]+\left(1-n_{t}\left(x_{1}^{\rho *}, x_{2}^{\rho *}\right)\right)\left[\lambda^{\rho} b_{t}^{l}+\left(1-\lambda^{\rho}\right) b_{t}^{h}-f_{c}\right] .
$$

To see that the capacity constraint can hurt both types of consumers, we need the following Lemma: 
Lemma 1 There exists an open set of parameter values $b_{t}^{l}, b_{t}^{h}, f_{e}, f_{c}, \lambda^{0}, z, n_{1}(1,1)$, and $n_{1}(0,0)$ that satisfy the following conditions:

S1) $\Delta b_{2}>f$

S2) $\Delta b_{1}\left(2 \lambda^{0}-1\right)>\Delta f>\Delta b_{2}\left(2 \lambda^{0}-1\right)$;

S3) $\frac{\left(2-z-n_{1}(0,0)\right)\left(\Delta b_{2}+\Delta f\right)}{\left(z-n_{1}(1,1)\right)\left(\Delta b_{2}-\Delta f\right)}>\frac{\lambda^{0}}{\left(1-\lambda^{0}\right)}>\frac{\left(1-n_{1}(0,0)\right)\left(\Delta b_{1}+\Delta f\right)}{\left(1-n_{1}(1,1)\right)\left(\Delta b_{1}-\Delta f\right)}$.

Proof. See Appendix A1.

Using this Lemma we obtain the following result:

Proposition 2 If conditions S1-S3 of Lemma 1 are fulfilled, and if the rationing scheme selects imperfectly, the following holds:

i) The unique equilibrium is given by $x_{1}^{0 *}=1, x_{2}^{0 *}=0, x_{1}^{1 *}=x_{2}^{1 *}=1$, and $x_{1}^{2 *}=x_{2}^{2 *}=0$;

ii) The absence of the ranking ex ante dominates its presence.

Proof. See Appendix A1.

If S1 and S2 hold, the capacity constraint is binding only when the ranking exists (see the proof of the proposition). Without the ranking, the consumers of each type request different goods. They can therefore all buy the good they request. With the ranking, all consumers request the same good: $e$ in case of the confirmative ranking, and $c$ in case of the surprise ranking. Due to imperfect discrimination, some consumers of both types cannot buy the good they request.

If $e$ is the high quality good, type 1 consumers lose on average. In this case the ranking induces all consumers to demand good $e$. Hence, some of the type 1 consumers no longer get the high quality good, whereas without the ranking, only type 1 consumers would have demanded good $e$ and all of them would have received it. On the other hand, if $c$ is the high quality good, type 1 consumers gain on average from the existence of the ranking, because with the ranking all of them try to avoid the low quality good $e$, and some of them succeed.

For type 2 consumers, the impact of the ranking for the different quality distributions is the opposite of that of consumers of type 1. If $e$ is the high quality good, all consumers of type 2 try to avoid the low quality good $c$, and some of them succeed. Hence, on average, 
they gain for this ranking outcome. If $c$ is the high quality good, they face competition from all the type 1 consumers, and hence some type 2 consumers have to consume the low quality good $e$. Therefore, in this case, type 2 consumers lose on average.

As a result, for each ranking outcome, one type of consumer loses on average and the other one gains. But, when condition S3 (in Lemma 1) is satisfied, the expected losses are larger than the expected gains for both types of consumers. In expectation, the ranking is thus bad for consumers of all types.

When are conditions S1-S3 fulfilled? When can we expect that the ranking is welfare decreasing? First, the quality must be important for both types of consumers, more important than the price difference (see S1 and remember that $\Delta b_{1}>\Delta b_{2}$ ). Second, the ex ante uncertainty must be in the middle range: Small enough that without the ranking it pays for the type 1 consumers to go for the expensive good, and high enough that it does not pay for type 2 consumers (see S2). Such a middle range ex ante uncertainty is also needed for the condition S3 to be satisfied. Finally, in case of a binding capacity constraint any discrimination in favor of one of the two types should be limited. If there is no discrimination in favor of a type, i.e. if $n_{1}(1,1)=\frac{z}{2}$ and $n_{1}(0,0)=1-\frac{z}{2}$, it is always the case that $\frac{\left(2-z-n_{1}(0,0)\right)\left(\Delta b_{2}+f\right)}{\left(z-n_{1}(1,1)\right)\left(\Delta b_{2}-f\right)}>\frac{\left(1-n_{1}(0,0)\right)\left(\Delta b_{1}+f\right)}{\left(1-n_{1}(1,1)\right)\left(\Delta b_{1}-f\right)}$. Therefore, there always exists a level of ex ante uncertainty such that S3 is fulfilled. On the other hand, if there is perfect discrimination in favor of one type, the existence of the ranking cannot be dominated by its absence.

Proposition 3 When the rationing scheme discriminates perfectly in favor of one type, the absence of the ranking can neither ex ante nor ex post dominate its presence.

\section{Proof. See Appendix A1.}

We have seen the possibility that both types of consumer are strictly better off without the ranking when there are capacity constraints and discrimination is imperfect. Without capacity constraints but with externalities, a similar result can be obtained. This is the focus of the following section. 


\subsection{The Welfare Implications of Consumption Externalities}

Consumption may lead to (positive or negative) externalities. Since there are no capacity constraints, all consumers get the good they want. Denote by $q^{m}\left(x_{1}, x_{2}\right)$ the externality experienced by a consumer of good $m$ when $x_{1}\left(x_{2}\right)$ type 1 (2) consumers consume good $e$. To simplify, we assume that the externalities depend only on the composition of actual consumers, and neither on the price nor on the quality of the good, i.e. $q^{e}\left(x_{1}, x_{2}\right)=q^{c}(1-$ $x_{1}, 1-x_{2}$ ). We assume that type 1 consumers provide more positive externalities (or less negative externalities) than type 2 consumers. More specifically, denote by $\Delta q\left(x_{1}, x_{2}\right)=$ $q^{e}\left(x_{1}, x_{2}\right)-q^{c}\left(x_{1}, x_{2}\right)$, i.e. the externality difference between consuming the two goods for a given allocation of consumers over the goods. We assume that the externality difference between consumers of good $e$ and $c$ is largest when all type 1 consumers choose $e$ and all type 2 consumers choose $c$. Formally

$$
\Delta q(1,0)>\max (\Delta q(1,1), \Delta q(0,0)) .
$$

Since $\Delta q(0,1)=-\Delta q(1,0)$ and $\Delta q(1,1)=-\Delta q(0,0)$ this implies

$$
\Delta q(0,1)<\min (\Delta q(1,1), \Delta q(0,0)) .
$$

Such an externality structure reflects, for example, a situation where the goods are study programs and the type 1 consumers are better students.

Again, denote by $x^{\rho *}=\left(x_{1}^{\rho *}, x_{2}^{\rho *}\right), \rho \in\{0,1,2\}$, the equilibrium. The equilibrium payoffs are given by

$U_{t}^{\rho}=x_{t}^{\rho *}\left[\lambda^{\rho} b_{t}^{h}+\left(1-\lambda^{\rho}\right) b_{t}^{l}-f_{e}+q^{e}\left(x_{1}^{\rho *}, x_{2}^{\rho *}\right)\right]+\left(1-x_{t}^{\rho *}\right)\left[\lambda^{\rho} b_{t}^{l}+\left(1-\lambda^{\rho}\right) b_{t}^{h}-f_{c}+q^{c}\left(x_{1}^{\rho *}, x_{2}^{\rho *}\right)\right]$

To see that both types of consumers might be better off without a ranking we need:

Lemma 2 There exists an open set of parameter values $b_{t}^{l}, b_{t}^{h}, f_{e}, f_{c}, \lambda^{0}, q^{e}\left(x_{1}, x_{2}\right)$, $x_{1}, x_{2} \in\{0,1\}$, that satisfy the following conditions:

E1) $\min \left\{\Delta b_{2}+\Delta q(1,1), \Delta b_{1}+\Delta q(0,1)\right\}>\Delta f>\max \left\{-\Delta b_{2}+\Delta q(0,0),-\Delta b_{1}+\right.$ $\Delta q(1,0)\}$;

E2) $\Delta b_{1}\left(2 \lambda^{0}-1\right)+\Delta q(0,0)>\Delta f>\Delta b_{2}\left(2 \lambda^{0}-1\right)+\Delta q(1,0)$;

E3) $q^{e}(1,0)-q^{e}(1,1)>\left(1-\lambda^{0}\right)\left(\Delta f+\Delta b_{1}\right)$;

E4) $\lambda^{0}\left(\Delta f-\Delta b_{2}\right)>q^{e}(1,1)-q^{e}(0,1)$. 
Proof. See Appendix A1.

Using this Lemma we obtain the following result:

Proposition 4 If conditions E1-E4 of Lemma 2 are fulfilled, it holds that:

i) The unique equilibrium is given by $x_{1}^{0 *}=1, x_{2}^{0 *}=0, x_{1}^{1 *}=x_{2}^{1 *}=1$, and $x_{1}^{2 *}=x_{2}^{2 *}=0$;

ii) The absence of the ranking ex, ante dominates its presence.

Proof. see Appendix A1.

If E1 and E2 hold, there exists a unique equilibrium where, without the ranking, the consumers of each type request different goods, while with the ranking all buy the higher ranked good.

Type 1 consumers are hurt by the ranking because, for both ranking outcomes, they experience worse consumption externalities than without the ranking. For the surprise ranking this negative effect is mitigated by the avoidance of the low quality good $e$, but for some parameter constellations, this positive effect is insufficient to overcome the negative one.

With a ranking, type 2 consumers benefit from better consumption externalities for both ranking outcomes. Yet, in case of a confirmative ranking, they can be stuck in a kind of prisoners' dilemma. The price difference of the goods can be such that even if $e$ is the high quality good, type 2 consumers would be better off if all of them were buying good $c$ (and all type 1 consumers good $e$ ) instead of all of them buying good $e$ (and all type 1 consumers good $e$ ). At the same time, each individual type 2 has an incentive to buy good $e$ for any distribution of consumers over the goods. As a result, a confirmative ranking leads to a worse outcome for type 2 consumers than no ranking at all.

For each ranking outcome one type of consumer loses on average and the other one gains. But with E3 and E4, the expected losses are larger than the expected gains for both types of consumers. In expectation, the ranking is thus bad for consumers of all types.

When are E1-E4 fulfilled? When can we expect that the ranking is welfare decreasing? E1 and E2 require that the price difference is in a middle range - large enough that, without rankings, only type 1 consumers buys the expensive good, but low enough that, 
with a ranking, both types buy the high quality good. For the same reason, the ex ante uncertainty about the goods' quality has to be in a middle range. E3 and E4 imply that the presence of the ranking leads to a Pareto deterioration. E3 states that the externality becomes much worse when type 2 peers are added to type 1 consumers. On the other hand, type 2 consumer suffer little when type 1 consumers are removed as their peers (see $\mathrm{E} 4)$.

We have seen that for fixed prices, capacity constraints and externalities might induce rankings to harm consumers. ${ }^{10}$ One might suspect that this result disappears with flexible prices. Yet the following section shows that flexible prices might actually allow for an additional detrimental effect of rankings.

\section{Price Competition}

In this section, we analyze the effects of rankings on consumers' welfare when two firms compete in prices. We consider markets without externalities and without capacity constraints. We show that rankings may affect consumers' welfare either positively or negatively. The reason for the negative effect is that more accurate information changes consumers' perception of product differentiation. This increases the market power of the firms and affects consumer welfare negatively. Our results also suggest some general conditions under which these effects are sufficiently strong to dominate the positive effects of information.

Firms set prices simultaneously. If there is a ranking, they fix prices after the ranking has been published but before consumers choose which good to request. In order to concentrate on the impact of rankings, we assume that there is no asymmetric information about the quality of the goods. When making their choices, firms have the same information as consumers. Without a ranking they know only the ex ante probability $\lambda^{0}$ that the expensive good is the one highly appreciated by the consumers. With a ranking, they

\footnotetext{
${ }^{10}$ If externalities and capacity constraints are present at the same time, the existence of a ranking might be even more harmful to the consumers. In a previous version of the paper we show that in this case the ranking might even be ex post dominated by its absence. This result requires an imperfect ranking that does not fully reveal the true qualities of the goods.
} 
know the qualities of the goods. Since there is no asymmetric information, prices do not signal any private information hold by the producers. Hence, prices depend only on the identity of the firm and on the ranking situation. Remember that $f_{m}^{\rho}$ denotes the price of $\operatorname{good} m$ in ranking situation $\rho$.

\subsection{Equilibrium Analysis}

To ensure the existence of an equilibrium, we need continuous demand functions. Individual consumers are assumed to have an idiosyncratic inclination for one of the goods. For ranking situation $\rho$, the expected utility of a consumer $i$ of type $t$ who buys good $e$ is

$$
U_{t, e}^{\rho}=\lambda^{\rho} b_{t}^{h}+\left(1-\lambda^{\rho}\right) b_{t}^{l}+y_{i}-f_{e}^{\rho}
$$

whereas the expected utility of buying $c$ is

$$
U_{t, c}^{\rho}=\lambda^{\rho} b_{t}^{l}+\left(1-\lambda^{\rho}\right) b_{t}^{c}-f_{c}^{\rho}
$$

Hence, $y_{i}$ measures the idiosyncratic inclination of consumer $i$ for good $e$ compared to good $c$. For each type $t, y_{i}$ is uniformly distributed on $-\delta$ and $\delta$ with $\delta>0$.

For the equilibrium analysis, we have to distinguish between two sets of parameter values: (i) parameters values implying that in equilibrium both goods are requested by consumers of both types in all ranking situations (heterogeneous demand), and (ii) parameters values implying that in equilibrium there is at least one ranking situation in which all consumers of one type request the same good (non-heterogeneous demand). Let $\psi^{\rho}=\left(2 \lambda^{\rho}-1\right)\left(\Delta b_{1}+\Delta b_{2}\right)$. As proven in Appendix A2, demand is heterogenous when $\frac{\psi^{\rho}}{3}-\Delta b_{t}\left(2 \lambda^{\rho}-1\right) \in(-\delta, \delta) \forall t, \rho$, and non-heterogeneous otherwise. This implies that for a generic combination of the other parameters there exists a $\bar{\delta}>0$ such that for all $\delta<\bar{\delta}$ the demand is non-heterogeneous.

\subsubsection{Heterogeneous Demand}

The following proposition characterizes equilibrium prices and the demand for goods $e$ and $c$ when, in equilibrium, both types of consumers request both types of goods: 
Proposition 5 When $\frac{\psi^{\rho}}{3}-\Delta b_{t}\left(2 \lambda^{\rho}-1\right) \in(-\delta, \delta) \forall t, \rho$, equilibrium prices are

$$
f_{e}^{\rho, *}=\delta+\frac{\psi^{\rho}}{6}>0, \text { and } f_{c}^{\rho, *}=\delta-\frac{\psi^{\rho}}{6}>0 \forall \rho
$$

In equilibrium, the demand for good e is:

$$
d_{e}\left(f_{e}^{\rho}, f_{c}^{\rho}\right)=1-\frac{\Delta f^{\rho, *}}{\delta}+\frac{\psi^{\rho}}{2 \delta} \in(0,2) \forall \rho
$$

and the demand for good $c$ is:

$$
d_{c}\left(f_{e}^{\rho}, f_{c}^{\rho}\right)=1+\frac{\Delta f^{\rho, *}}{\delta}-\frac{\psi^{\rho}}{2 \delta} \in(0,2) \forall \rho
$$

Proof. See Appendix A2.

For the ranking situation $\rho$, we can compute the expected utility of a randomly selected type $t$ consumer given the equilibrium prices $\left(f_{e}^{\rho, *}, f_{c}^{\rho, *}\right)$ :

$$
U_{t}^{\rho}=\int_{0}^{\Delta f^{\rho, *}-\Delta b_{t}\left(2 \lambda^{\rho}-1\right)}\left(L_{t}^{\rho}-f_{c}^{\rho, *}\right) \frac{1}{2 \delta} d y_{t, i}+\int_{\Delta f^{\rho}-\Delta b_{t}\left(2 \lambda^{\rho}-1\right)}^{\delta}\left(H_{t}^{\rho}+y_{t, i}-f_{e}^{\rho, *}\right) \frac{1}{2 \delta} d y_{t, i}
$$

with $L_{t}^{\rho}=\lambda^{\rho} b_{t}^{l}+\left(1-\lambda^{\rho}\right) b_{t}^{h}$ and $H_{t}^{\rho}=\lambda^{\rho} b_{t}^{h}+\left(1-\lambda^{\rho}\right) b_{t}^{l}$.

This boils down to

$$
\begin{aligned}
U_{t}^{\rho}= & \frac{L_{t}^{\rho}-f_{c}^{\rho, *}}{2 \delta}\left(\Delta f^{\rho, *}-\Delta b_{t}\left(2 \lambda^{\rho}-1\right)+\delta\right)+\frac{H_{t}^{\rho, *}-f_{e}^{\rho, *}}{2 \delta}\left(\delta-\Delta f^{\rho, *}+\Delta b_{t}\left(2 \lambda^{\rho}-1\right)(y)\right. \\
& +\frac{1}{2 \delta}\left(\frac{\delta^{2}}{2}-\frac{\left(\Delta f^{\rho, *}-\Delta b_{t}\left(2 \lambda^{\rho}-1\right)\right)^{2}}{2}\right) .
\end{aligned}
$$

As already mentioned, the case of heterogeneous demand requires that $\delta$ is not too low. If the idiosyncratic inclinations are important enough, consumers of both types demand both goods in equilibrium.

\subsubsection{Non-Heterogeneous Demand}

The main difference with the previous case concerns equilibrium prices. There are many potential combinations of $t$ and $\rho$ for which $\frac{\psi^{\rho}}{3}-\Delta b_{t}\left(2 \lambda^{\rho}-1\right) \notin(-\delta, \delta)$. The analysis of the different cases is very similar. To avoid redundancies, we detail (in Appendix A3) only two of these cases (those that will be used in Proposition 7). In case (A), equilibrium prices are such that all type 1 consumers request good $e$ when the ranking 
is confirmative (i.e. $\rho=1$ ). For any other ranking situation (i.e. $\rho=0$ or 2), type 1 consumers request both types of goods. Case (A) arises when $\frac{\psi^{1}}{3}-\Delta b_{1}\left(2 \lambda^{1}-1\right)<-\delta$, and $\frac{\psi^{\rho}}{3}-\Delta b_{t}\left(2 \lambda^{\rho}-1\right) \in(-\delta, \delta)$ for all other $\rho$ and $t$. In case $(\mathrm{B})$, equilibrium prices are such that all type 1 consumers request good $c$ when the ranking is surprising, and both goods for all other ranking situations. Case (B) arises when $\frac{\psi 2}{3}-\Delta b_{1}\left(2 \lambda^{2}-1\right)>\delta$, and $\frac{\psi^{\rho}}{3}-\Delta b_{t}\left(2 \lambda^{\rho}-1\right) \in(-\delta, \delta)$ for all other $\rho$ and $t$.

We are now in a position to analyze the welfare implications of rankings when firms are competing in prices.

\subsection{Welfare Analysis}

In this section, we analyze the effect of rankings on consumers' welfare for flexible prices. The benefit of a ranking is to reduce uncertainty about the quality of the two goods. But when firms compete in prices, the ranking can have a negative effect on consumer welfare through its effect on firms' market power. In a certain sense, the ranking increases the differentiation of the two goods, and allows firms to enforce higher prices. We identify conditions under which one or the other effect dominates.

The net effect of the ranking is always positive when demand is heterogeneous, i.e. when, in equilibrium, consumers of both types consume both goods (Proposition 6). The net effect of the ranking can be negative when the information provided by some ranking outcome induces non-heterogeneous demand, i.e. when all consumers of (at least) one type consume the same good (Proposition 7). In particular, this happens when type 1 consumers, who care relatively more about the quality of the good, exhibit only small idiosyncratic inclinations towards a good. In this case the firm who produces the highest ranked good can increase its price at the margin without losing any its type 1 consumers. The ranking thus significantly increases the market power of that firm.

The following proposition shows that the ranking always has a positive effect on consumers' welfare when the demand is heterogeneous.

Proposition 6 If, in equilibrium, both types of consumers request both types of goods for all ranking situations, the presence of the ranking ex ante dominates its absence.

Proof. see Appendix A2 
With non-heterogeneous demand, the ranking may have a negative effect on consumer welfare even when evaluated after the result of the ranking is known (i.e. ex post).

Proposition 7 With flexible prices, there is an open set of parameter values $\delta, b_{t}^{l}$, $b_{t}^{h}$, and $\lambda^{0}$ such that the absence of the ranking ex ante as well as ex post dominates its presence.

Proof. see Appendix A2

The flexibility of prices does not solve the problem of rankings as identified in the previous section. On the contrary, with flexible prices the ranking might create an additional problem for the consumers because it could increase the market power of the firm who "wins" the ranking. As Proposition 6 shows, this can only happen for non-heterogeneous demand. To see the intuition behind this result, consider parameters such that the demand is heterogeneous in absence of the ranking, but, with the ranking, all type 1 consumers demand the "winning" good. In absence of the ranking, any marginal increase in the price leads to a marginal decrease in the demand of both types of consumers. But with the ranking, a marginal increase of the price of higher ranked good has no impact on its demand by type 1 consumers. Hence, the ranking substantially increases the market power of the winning firm when it induces non-heterogeneous demand. But if the demand is heterogeneous for all ranking situations, this cannot happen. Therefore, the ranking induces a larger increase in the winning firm's market power with non-heterogeneous than with heterogeneous demand.

Obviously, it is more likely that demand is non-heterogeneous the lower $\delta$ is. Recall that a low $\delta$ means that the idiosyncratic inclinations of the consumers are relatively unimportant compared to the quality of the good. Ironically, when the information provided by the ranking is very important for the consumers, and when the market is in principle rather competitive, it is most probable that the ranking will hurt consumers. In this case the outcome of a ranking leads to a big shift in demand, leading to an increase of the market power of the "winning" firm and hurting all types of consumers in the end. 


\section{Conclusion}

In this paper we have demonstrated that the existence of rankings can be harmful to all consumers when the good is rationed, when there are consumption externalities, and/or when firms have market power. These harmful effects are more likely the less discriminatory the rationing scheme is, the more important consumption externalities are, and the more important the good's quality is relative to the consumers' idiosyncratic inclinations for a particular good. It seems plausible that rationing, externalities, and quality play an important role in markets for education programs. The same holds, e.g., for medical services. Hence, in these markets, it is a priori unclear whether rankings are beneficial for consumers. But of course the analysis of the existence and the size of harmful effects of rankings for a particular market is left for future empirical research.

\section{References}

[1] Anderson, S., and R. Renault (2000), Consumer Information and Firm Pricing: Negative Externalities from Improved Information, International Economic Review, 41(3), $721-742$.

[2] Anderson, S., and R. Renault (2009), Comparative Advertising: Disclosing Horizontal Match Information, RAND Journal of Economics, 40(3), 558-581.

[3] Dranove, D., and G. Jin (2010), Quality Disclosure and Certification: Theory and Practice, Journal of Economic Literature, 48(4), 935-963.

[4] Dranove, D., D. Kessler, M. McClellan, and M. Satterthwaite (2003), Is More Information Better? The Effects of "Report Cards" on Health Care Providers, Journal of Political Economy, 111(3), 555-588.

[5] Gavazza, A., and A. Lizzeri (2007), The Perils of Transparency in Bureaucracies, American Economic Review, 97(2), Papers and Proceedings, 300-305.

[6] Glazer, J., and T. McGuire (2006), Optimal Quality Reporting in Markets for Health Plans, Journal of Health Economics, 25, 295-310. 
[7] Glazer, J., T. McGuire, Z. Cao, and A, Zaslavsky (2008), Using Global Ratings of Health Plans to Improve the Quality of Health Care, Journal of Health Economics, 27(5), 1182-1195.

[8] Jin, G. and P. Leslie (2003), The Effects of Information on Product Quality: Evidence from Restaurant Hygiene Grade Cards, Quarterly Journal of Economics, 118(2), 40951.

[9] Kalaitzidakis, P., T. Mauneas, and T. Stengos (2010), An updated ranking of academic journals in economics, mimeo.

[10] Luca, M. (2011), Reviews, Reputation, and Revenue: The Case of Yelp.com, Harvard Business School Working Paper, 12-016.

[11] Luca, M. and J. Smith (2012), Salience in Quality Disclosure: Evidence from the U.S. News College Rankings, Journal of Economics and Management Strategy, forthcoming.

[12] Morris, S., and H.S. Shin (2002), Social Value of Public Information, American Economic Review, 92(5), 1521-1534.

[13] Palacios-Huerta, I., and O. Volij (2004), The measurement of intellectual influence, Econometrica, 72, 963-977.

[14] Pope, D. (2009), Reacting to Rankings: Evidence from 'America's Best Hospitals', Journal of Health Economics, 28(6), 1154-1165.

[15] Sorensen, A. (2007), Bestseller Lists and Product Variety, Journal of Industrial Economics, 55(4), 715-738.

\section{Appendices}

\section{Appendix A1: Proofs of Section 3}

Proof of Proposition 1. In a situation with fixed prices, no capacity constraints, and no externalities, the "game" is actually an individual decision problem. Therefore, the first part of the proposition is trivially true. 
For the proof of the second part, let $f_{c}=0, f_{e}=2, b_{1}^{l}=b_{2}^{l}=1, b_{1}^{h}=5, b_{2}^{h}=4$, and $\lambda^{0}=0.7$. Because of the equilibrium condition, it holds in equilibrium that $x_{1}^{0}=x_{1}^{2}=0, x_{1}^{1}=1$ and $x_{2}^{0}=x_{2}^{2}=0$, $x_{2}^{1}=1$. This gives $U_{1}^{0}=2.2, U_{1}^{1}=3, U_{1}^{2}=5$, and $U_{2}^{0}=1.9, U_{2}^{1}=2, U_{2}^{2}=4$. These equilibrium payoffs fulfill the condition that the presence of the ranking for ex post dominates its absence. Furthermore, all differences of equilibrium payoffs are strictly positive. Hence, there is an open neighborhood of these parameter values such that the presence of a ranking ex post dominates its absence.

Proof of Lemma 1. Take the parameter values $f_{c}=0, f_{e}=2, b_{1}^{l}=b_{2}^{l}=1, b_{1}^{h}=5, b_{2}^{h}=3.2$, $\lambda^{0}=0.85$, and $z=1.2$. These values fulfill the conditions S1-S3 with strict inequality. Since the conditions are continuous in the parameters, there exists on open set of parameters fulfilling these conditions.

Proof of Proposition 2. The proof consists of three parts. First, we analyze the properties of the probability of an agent to be able to buy a particular good. Second, we prove that the stated behavior is indeed the unique equilibrium. Third, we show that the absence of the ranking ex ante dominates its presence.

1. The probability of an agent to be able to buy a particular good: This probability depends on his type, his strategy, and the strategy distribution of the whole population. Denote by $p_{t}^{m}\left(s_{i}, x_{1}, x_{2}\right)$ the probability of an agent of type $t$ to buy good $m$ when his strategy is $s_{i}$ and $\left(x_{1}, x_{2}\right)$ is the strategy distribution of the whole population. Since the whole market can be served by both producers together and each agent gets one good, $p_{t}^{m}\left(s_{i}, x_{1}, x_{2}\right)=1-p_{t}^{m^{\prime}}\left(s_{i}, x_{1}, x_{2}\right)$ for $m \neq m^{\prime}$. Hence, we simplify notation by setting $p_{t}^{e}\left(s_{i}, x_{1}, x_{2}\right)=p_{t}\left(s_{i}, x_{1}, x_{2}\right)$. In order to further characterize $n_{t}\left(x_{1}, x_{2}\right)$ and $p_{t}\left(s_{i}, x_{1}, x_{2}\right)$ we have to distinguish between three cases: (i) $x_{1}+x_{2}>z$, (ii) $z \geq \max \left(x+x_{2}, 2-x_{1}-x_{2}\right.$ ), and (iii) $2-x_{1}-x_{2}>z$.

(i) If $x_{1}+x_{2}>z$, there is excess demand for good $e$. Since the good is sold up to the capacity constraint, it holds that $n_{1}\left(x_{1}, x_{2}\right)=z-n_{2}\left(x_{1}, x_{2}\right)$. Since the selection process is not perfect, $x_{1}>n_{1}>0$, $x_{2}>n_{2}>0$, and if $x_{1}$ strictly increases and $x_{2}$ is constant, $n_{1}$ strictly increases and $n_{2}$ strictly decreases. If $x_{2}$ strictly increases and $x_{1}$ is constant, $n_{1}$ strictly decreases and $n_{2}$ strictly increases. The probability of getting good $e$ is given by:

$$
\begin{aligned}
& p_{1}\left(e, x_{1}, x_{2}\right)=\frac{n_{1}\left(x_{1}, x_{2}\right)}{x_{1}} ; p_{2}\left(e, x_{1}, x_{2}\right)=\frac{z-n_{1}\left(x_{1}, x_{2}\right)}{x_{2}} ; \\
& p_{1}\left(c, x_{1}, x_{2}\right)=p_{2}\left(c, x_{1}, x_{2}\right)=0 .
\end{aligned}
$$

(ii) If $z \geq \max \left(x_{1}+x_{2}, 2-x_{1}-x_{2}\right)$, there is no excess demand for any of the goods, and each consumer gets the good he wants. This implies that $n_{1}\left(x_{1}, x_{2}\right)=x_{1}$ and $n_{2}\left(x_{1}, x_{2}\right)=x_{2}$. Furthermore

$$
\begin{aligned}
& p_{1}\left(e, x_{1}, x_{2}\right)=p_{2}\left(e, x_{1}, x_{2}\right)=1 \\
& p_{1}\left(c, x_{1}, x_{2}\right)=p_{2}\left(c, x_{1}, x_{2}\right)=0 .
\end{aligned}
$$


(iii) If $2-x_{1}-x_{2}>z$, there is excess demand for good $c$, and $1-n_{1}\left(x_{1}, x_{2}\right)=z-\left(1-n_{2}\left(x_{1}, x_{2}\right)\right)$. Since the selection process is the same for both types of producers, $1-n_{t}\left(x_{1}, x_{2}\right)=n_{t}\left(1-x_{1}, 1-x_{2}\right)$. The mass of consumers of type 1 who consume good $c, 1-n_{1}\left(x_{1}, x_{2}\right)$, strictly increases in the number of type 1 applications for $c, 1-x_{1}$, and strictly decreases in the number of type 2 applications for $c, 1-x_{2}$. The probability of getting good $e$ is given by

$$
\begin{aligned}
& p_{1}\left(e, x_{1}, x_{2}\right)=p_{2}\left(e, x_{1}, x_{2}\right)=1 \\
& p_{1}\left(c, x_{1}, x_{2}\right)=1-\frac{n_{1}\left(1-x_{1}, 1-x_{2}\right)}{1-x_{1}} ; p_{2}\left(c, x_{1}, x_{2}\right)=1-\frac{n_{2}\left(1-x_{1}, 1-x_{2}\right)}{1-x_{1}} .
\end{aligned}
$$

Note that for all three cases, $n_{1}\left(x_{1}, x_{2}\right)$ strictly increases in $x_{1}$ and weakly decreases in $x_{2}$. Conversely, $n_{2}\left(x_{1}, x_{2}\right)$ strictly increases in $x_{2}$ and weakly decreases in $x_{1}$. Furthermore, $p_{t}\left(e, x_{1}, x_{2}\right)>p_{t}\left(c, x_{1}, x_{2}\right)$ - the probability of getting good $e$ is higher when one applies for $e$ than when one does not. The same holds for good $c$.

2. The unique equilibrium: We have to show that $x_{1}^{0 *}=1, x_{2}^{0 *}=0, x_{1}^{1 *}=x_{2}^{1 *}=1$, and $x_{1}^{2 *}=x_{2}^{2 *}=0$ is the unique equilibrium. From the first part of the proof, we know that the likelihood of getting a particular good is strictly higher when demanding this good than when demanding the other good. Hence, for generic parameter constellations a consumer will demand good $m$ iff the expected payoff from consuming $m$ is larger than that of consuming $m^{\prime}$.

Denote by $u_{t}^{\rho}(m)$ the payoff of a consumer of type $t$ choosing $m$ in ranking situation $\rho$. Consider ranking situation 0. From (2) and (3), we have that

$$
\begin{aligned}
& u_{1}^{0}(e)>u_{1}^{0}(c) \text { iff } \Delta b_{1}\left(2 \lambda^{0}-1\right)>\Delta f \\
& u_{2}^{0}(c)>u_{2}^{0}(e) \text { iff } \Delta b_{2}\left(2 \lambda^{0}-1\right)<\Delta f .
\end{aligned}
$$

These conditions are S2, and hence in any equilibrium it must hold that $x_{1}^{0 *}=1, x_{2}^{0 *}=0$.

Next, consider ranking situation 1 . From (2) and (3), we have that

$$
\begin{aligned}
& u_{1}^{1}(e)>u_{1}^{1}(c) \text { iff } \Delta b_{1}>\Delta f \\
& u_{2}^{1}(e)>u_{2}^{1}(c) \text { iff } \Delta b_{2}>\Delta f .
\end{aligned}
$$

Since by the definition of the types, $\Delta b_{1}>\Delta b_{2}$, these conditions are satisfied if $\mathrm{S} 1$ is satisfied. Thus, in any equilibrium it must hold that $x_{1}^{1 *}=x_{2}^{1 *}=1$.

Finally, consider ranking situation 2. From (2) and (3), we have that

$$
\begin{aligned}
& u_{1}^{2}(c)>u_{1}^{2}(e) \text { iff } \Delta b_{1}+\Delta f>0 \\
& u_{2}^{2}(c)>u_{2}^{2}(e) \text { iff } \Delta b_{2}+\Delta f>0
\end{aligned}
$$

These conditions are of course always satisfied. Thus, in any equilibrium it must hold that $x_{1}^{2 *}=x_{2}^{2 *}=0$. 
3. The absence of the ranking ex ante dominates its presence: In ranking situation 0 , the equilibrium payoffs are given by:

$$
\begin{aligned}
U_{1}^{0} & \left.=\lambda^{0}\left(-f_{e}+b_{1}^{h}\right)+\left(1-\lambda^{0}\right)\left(-f_{e}+b_{1}^{l}\right)\right] \\
U_{2}^{0} & \left.=\lambda^{0}\left(-f_{c}+b_{t}^{l}\right)+\left(1-\lambda^{0}\right)\left(-f_{c}+b_{t}^{h}\right)\right]
\end{aligned}
$$

In ranking situation 1 , they are given by:

$$
U_{t}^{1}=n_{t}(1,1)\left(-f_{e}+b_{t}^{h}\right)+\left(1-n_{t}(1,1)\right)\left(-f_{c}+b_{t}^{l}\right) .
$$

In ranking situation 2, they are given by:

$$
U_{t}^{2}=n_{t}(0,0)\left(-f_{e}+b_{t}^{l}\right)+\left(1-n_{t}(0,0)\right)\left(-f_{c}+b_{t}^{h}\right)
$$

The condition $U_{1}^{0}>\lambda^{0} U_{1}^{1}+\left(1-\lambda^{0}\right) U_{1}^{2}$ boils down to

$$
\frac{\lambda^{0}}{1-\lambda^{0}}>\frac{\left(1-n_{1}(0,0)\right)\left(\Delta b_{1}+\Delta f\right)}{\left(1-n_{1}(1,1)\right)\left(\Delta b_{1}-\Delta f\right)}
$$

Similarly, the condition $U_{2}^{0}>\lambda^{0} U_{2}^{1}+\left(1-\lambda^{0}\right) U_{2}^{2}$ boils down to

$$
\frac{n_{2}(0,0)\left(\Delta b_{2}+\Delta f\right)}{n_{2}(1,1)\left(\Delta b_{2}-\Delta f\right)}>\frac{\lambda^{0}}{1-\lambda^{0}}
$$

From $n_{1}(0,0)=1-n_{1}(1,1)$ we get $n_{2}(0,0)=1-\left(z-\left(1-n_{1}(0,0)\right)\right)=2-z-n_{1}(0,0)$. Given that $n_{2}(1,1)=z-n_{1}(1,1)$, condition (5) boils down to

$$
\frac{\left(2-z-n_{1}(0,0)\right)\left(\Delta b_{2}+\Delta f\right)}{\left(z-n_{1}(1,1)\right)\left(\Delta b_{2}-\Delta f\right)}>\frac{\lambda^{0}}{1-\lambda^{0}} .
$$

Therefore, the absence of the ranking ex ante dominates its presence when condition S3 of Lemma 1 is fulfilled (on top of S1 and S2).

Proof of Proposition 3. Let $\hat{t}$ be the type of consumers which is favored. This implies every consumer of type $\hat{t}$ gets the good he wants, i.e. $n_{\hat{t}}^{\rho}=x_{\hat{t}}^{\rho}$. Therefore, these consumers face an individual decision problem. Hence, for each possible ranking outcomes their payoff is weakly larger than their expected payoff without the ranking. Therefore the absence of the ranking can neither ex ante nor ex post dominate its presence.

Proof of Lemma 2. Take the parameter values $f_{c}=0, f_{e}=0.35, b_{1}^{l}=b_{2}^{l}=1, b_{1}^{h}=1.54$, $b_{2}^{h}=1.3, \lambda^{0}=0.9, q^{e}(1,0)=q^{c}(0,1)=0.8, q^{e}(1,1)=q^{c}(0,0)=0.71, q^{e}(0,0)=q^{c}(1,1)=0.65$, and $q^{e}(0,1)=q^{c}(1,0)=0.7$. These values fulfill the conditions E1-E4 with strict inequality. Since the conditions are continuous in the parameters, there exists on open set of parameters fulfilling these conditions. 
Proof of Proposition 4. The proof proceeds in two steps. First, we show that the unique equilibrium is indeed as stated in the proposition, Then, we prove the welfare properties.

1. The unique equilibrium: We have to show that $x_{1}^{0 *}=1, x_{2}^{0 *}=0, x_{1}^{1 *}=x_{2}^{1 *}=1$, and $x_{1}^{2 *}=x_{2}^{2 *}=0$ is the unique equilibrium. Denote by $u_{t}^{\rho}(m)$ the payoff of a consumer of type $t$ choosing $m$ in ranking situation $\rho$. For any $x_{1}^{\rho}, x_{2}^{\rho}$ it holds that

$$
u_{t}^{\rho}(e)-u_{t}^{\rho}(c)=\Delta b_{t}\left(2 \lambda^{0}-1\right)+\Delta q\left(x_{1}^{\rho}, x_{2}^{\rho}\right)-\Delta f
$$

Since $\Delta b_{1}>\Delta b_{2}, u_{1}^{\rho}(e)-u_{1}^{\rho}(c)>u_{2}^{\rho}(e)-u_{2}^{\rho}(c)$ for $\rho \in\{0,1\}$ and $u_{1}^{\rho}(e)-u_{1}^{\rho}(c)<u_{2}^{\rho}(e)-u_{2}^{\rho}(c)$ for $\rho=2$. In equilibrium, it cannot happen that either $x_{1}^{0 *}=0, x_{2}^{0 *}=1$, or $x_{1}^{1 *}=0, x_{2}^{1 *}=1$, or $x_{1}^{2 *}=1, x_{2}^{2 *}=0$.

Consider first the ranking situation 0 . Fixing the choice of the other consumers at their equilibrium value of $x_{1}^{0 *}=1$ and $x_{2}^{0 *}=0$, the equilibrium conditions for consumers of type 1 and type 2 are given by

$$
\begin{aligned}
& u_{1}^{0}(e) \geq u_{1}^{0}(c) \text { iff } \Delta b_{1}\left(2 \lambda^{0}-1\right)+\Delta q(1,0) \geq \Delta f, \text { and } \\
& u_{2}^{0}(c) \geq u_{2}^{0}(e) \text { iff } \Delta b_{2}\left(2 \lambda^{0}-1\right)+\Delta q(1,0) \leq \Delta f,
\end{aligned}
$$

respectively. Since $\Delta q(1,0)>\Delta q(0,0)$ both conditions are met due to E2. To show that in any equilibrium $x_{1}^{0 *}=1, x_{2}^{0 *}=0$ holds, we still have to exclude $x_{1}^{0}=x_{2}^{0}=0$ and $x_{1}^{0}=x_{2}^{0}=1$ as part of an equilibrium. If $x_{1}^{0}=x_{2}^{0}=0, \Delta b_{1}\left(2 \lambda^{0}-1\right)+\Delta q(0,0) \leq \Delta f$. But this is excluded by E2. If $x_{1}^{0}=x_{2}^{0}=1$, $\Delta b_{2}\left(2 \lambda^{0}-1\right)+\Delta q(1,1) \geq \Delta f$. But this excluded by E2 since $\Delta q(1,0)>\Delta q(1,1)$.

Next, consider the ranking situation 1. Fixing the choice of the other consumers at their equilibrium value of $x_{1}^{1 *}=x_{2}^{1 *}=1$, the equilibrium conditions for consumers of type 1 and type 2 are given by

$$
\begin{aligned}
& u_{1}^{1}(e) \geq u_{1}^{1}(c) \text { iff } \Delta b_{1}+\Delta q(1,1) \geq \Delta f, \text { and } \\
& u_{2}^{1}(e) \geq u_{2}^{1}(c) \text { iff } \Delta b_{2}+\Delta q(1,1) \geq \Delta f,
\end{aligned}
$$

respectively. Since $\Delta q(1,1)>\Delta q(0,1)$ these conditions are guaranteed by E1. To show that in any equilibrium $x_{1}^{1 *}=x_{2}^{1 *}=1$ holds, we still have to exclude $x_{1}^{1}=x_{2}^{1}=0$ and $x_{1}^{1}=1, x_{2}^{1}=0$ as part of an equilibrium. If $x_{1}^{1}=x_{2}^{1}=0, \Delta b_{1}+\Delta q(0,0)<\Delta f$. But this is excluded by E2 since $\lambda^{0}<1$. If $x_{1}^{1}=1$, $x_{2}^{1}=0$, we need $\Delta b_{2}+\Delta q(1,0) \leq \Delta f$. But, given $\Delta q(1,0)>\Delta q(1,1)$, this excluded by E1.

Finally, consider the ranking situation 2. Fixing the choice of the other consumers at their equilibrium value of $x_{1}^{2 *}=x_{2}^{2 *}=0$, the equilibrium conditions for consumers of type 1 and type 2 are given by

$$
\begin{aligned}
& u_{1}^{2}(c) \geq u_{1}^{2}(e) \text { iff }-\Delta b_{1}+\Delta q(0,0) \leq \Delta f, \text { and } \\
& u_{2}^{2}(c) \geq u_{2}^{2}(e) \text { iff }-\Delta b_{2}+\Delta q(0,0) \leq \Delta f
\end{aligned}
$$

respectively. Since $\Delta q(1,0)>\Delta q(0,0)$, these conditions are guaranteed by E1. To show that in any equilibrium $x_{1}^{2 *}=x_{2}^{2 *}=0$ holds, we still have to exclude $x_{1}^{2}=x_{2}^{2}=1$ and $x_{1}^{2}=0, x_{2}^{2}=1$ as part of an equilibrium. If $x_{1}^{2}=x_{2}^{2}=1,-\Delta b_{1}+\Delta q(1,1) \geq \Delta f$. But, given $\Delta q(1,0)>\Delta q(1,1)$, this is excluded by 
E1. If $x_{1}^{2}=0, x_{2}^{2}=1$, we need $-\Delta b_{2}+\Delta q(0,1) \geq \Delta f$. But, given $\Delta q(0,1)<\Delta q(0,0)$, this is excluded by E1.

\section{Conditions for the ex ante dominance of the absence of the ranking:}

Without the ranking, we have $x_{1}^{0 *}=1$ and $x_{2}^{0 *}=0$, giving

$$
\begin{aligned}
& U_{1}^{0}=\lambda^{0}\left(-f_{e}+b_{1}^{h}+q^{e}(1,0)\right)+\left(1-\lambda^{0}\right)\left(-f_{e}+b_{1}^{l}+q^{e}(1,0)\right), \text { and } \\
& U_{2}^{0}=\lambda^{0}\left(-f_{c}+b_{2}^{l}+q^{c}(1,0)\right)+\left(1-\lambda^{0}\right)\left(-f_{c}+b_{2}^{h}+q^{c}(1,0)\right) .
\end{aligned}
$$

For the confirmative ranking, we have $x_{1}^{1 *}=x_{2}^{1 *}=1$, leading to

$$
U_{t}^{1}=-f_{e}+b_{t}^{h}+q^{e}(1,1)
$$

For the surprise ranking, we have $x_{1}^{2 *}=x_{2}^{2 *}=0$, implying

$$
U_{t}^{2}=-f_{c}+b_{t}^{h}+q^{c}(0,0)
$$

Taking into account that $q^{c}(0,0)=q^{e}(1,1)$, the condition $U_{1}^{0}>\lambda^{0} U_{1}^{1}+\left(1-\lambda^{0}\right) U_{1}^{2}$ becomes

$$
q^{e}(1,0)-q^{e}(1,1)>\left(1-\lambda^{0}\right)\left(\Delta f+\Delta b_{1}\right) .
$$

Taking into account that $q^{c}(1,0)=q^{e}(0,1)$ and $q^{c}(0,0)=q^{e}(1,1)$, the condition $U_{2}^{0}>\lambda^{0} U_{2}^{1}\left(n^{1}\right)+(1-$ $\left.\lambda^{0}\right) U_{2}^{2}$ becomes

$$
\lambda^{0}\left(\Delta f-\Delta b_{2}\right)>q^{e}(1,1)-q^{e}(0,1)
$$

Therefore, the absence of the ranking ex ante dominates its presence when condition E3 and E4 of Lemma 2 are fulfilled (on top of E1 and E2).

\section{Appendix A2: Proofs of Section 4}

Proof of Proposition 5. We solve the game backward. Ignoring for the moment the fact that demand cannot be below zero and above 2 , the demand for $\operatorname{good} e$ is:

$$
\begin{aligned}
d_{e}\left(f_{e}^{\rho}, f_{c}^{\rho}\right) & =\underbrace{1-\frac{\Delta f^{\rho}-\Delta b_{1}\left(2 \lambda^{\rho}-1\right)+\delta}{2 \delta}}_{\text {Fraction of type-1 with } y_{1} \geq \Delta f^{\rho}-\Delta b_{1}\left(2 \lambda^{\rho}-1\right)}+\underbrace{1-\frac{\Delta f^{\rho}-\Delta b_{2}\left(2 \lambda^{\rho}-1\right)+\delta}{2 \delta}}_{\text {Fraction of type-2 with } y_{2} \geq \Delta f^{\rho}-\Delta b_{2}\left(2 \lambda^{\rho}-1\right)} \\
& =1-\frac{\Delta f^{\rho}}{\delta}+\frac{\psi^{\rho}}{2 \delta} .
\end{aligned}
$$

Similarly, the demand for good $c$ is:

$$
d_{c}\left(f_{e}^{\rho}, f_{c}^{\rho}\right)=1+\frac{\Delta f^{\rho}}{\delta}-\frac{\psi^{\rho}}{2 \delta} .
$$

There are parameters values such that $d_{e}\left(f_{e}^{\rho}, f_{c}^{\rho}\right)$ and/or $d_{c}\left(f_{e}^{\rho}, f_{c}^{\rho}\right) \notin(0,2)$. But we will show that in equilibrium $d_{e}\left(f_{e}^{\rho}, f_{c}^{\rho}\right)$ and $d_{c}\left(f_{e}^{\rho}, f_{c}^{\rho}\right) \in(0,2)$ whenever $\frac{\psi^{\rho}}{3}-\Delta b_{t}\left(2 \lambda^{\rho}-1\right) \in(-\delta, \delta) \forall t, \rho$. 
Given these demand functions, we can derive the best responses of both firms to the strategy of the other by maximizing profits, denoted by $\pi_{m}\left(f_{e}^{\rho}, f_{c}^{\rho}\right)$. For good $e$, we have the following best response function:

$$
f_{e}^{\rho}\left(f_{c}^{\rho}\right)=\frac{\delta}{2}+\frac{f_{c}^{\rho}}{2}+\frac{\psi^{\rho}}{4}
$$

For good $c$, we have:

$$
f_{c}^{\rho}\left(f_{e}^{\rho}\right)=\frac{\delta}{2}+\frac{f_{e}^{\rho}}{2}-\frac{\psi^{\rho}}{4} .
$$

Using (8) and (9), we find the equilibrium prices:

$$
\begin{aligned}
& f_{e}^{\rho, *}=\delta+\frac{\psi^{\rho}}{6}, \\
& f_{c}^{\rho, *}=\delta-\frac{\psi^{\rho}}{6} .
\end{aligned}
$$

Using equilibrium prices, we can compute $d_{e}\left(f_{e}^{\rho, *}, f_{c}^{\rho, *}\right)$ and $d_{c}\left(f_{e}^{\rho, *}, f_{c}^{\rho *}\right)$, the demand for good $e$ and $c$ when prices are $\left(f_{e}^{\rho, *}, f_{c}^{\rho, *}\right)$. We obtain that $d_{e}\left(f_{e}^{\rho, *}, f_{c}^{\rho, *}\right)$ and $d_{c}\left(f_{e}^{\rho, *}, f_{c}^{\rho *}\right) \in(0,2)$ whenever $\frac{\psi^{\rho}}{3}-\Delta b_{t}\left(2 \lambda^{\rho}-1\right) \in(-\delta, \delta) \forall t, \rho$. This means that both types of consumers request both types of goods.

It remains to show that the prices as stated by (10) and (10) are always positive. From $\psi^{\rho}=$ $\left(2 \lambda^{\rho}-1\right)\left(\Delta b_{1}+\Delta b_{2}\right)$, we have that $\frac{\psi^{\rho}}{3}-\Delta b_{t}\left(2 \lambda^{\rho}-1\right) \in(-\delta, \delta) \forall t, \rho$ implies

$$
\begin{aligned}
& \delta>\left(2 \lambda^{\rho}-1\right)\left(\Delta b_{t}-\frac{\left(\Delta b_{1}+\Delta b_{2}\right)}{3}\right), \text { and } \\
& \delta>\left(2 \lambda^{\rho}-1\right)\left(\frac{\left(\Delta b_{1}+\Delta b_{2}\right)}{3}-\Delta b_{t}\right) .
\end{aligned}
$$

For $\rho=0,1,2 \lambda^{\rho}-1>0$. Therefore, the maximum of the lower bound for $\delta$ is

$$
\delta>\left(2 \lambda^{\rho}-1\right)\left(\frac{2 \Delta b_{1}-\Delta b_{2}}{3}\right)
$$

For $\rho=2$, the maximum is

$$
\delta>\left(2 \lambda^{\rho}-1\right)\left(\frac{\Delta b_{2}-2 \Delta b_{1}}{3}\right)
$$

If $\rho=0$, then $f_{e}^{0, *}>f_{c}^{0, *}=\delta-\frac{\left(2 \lambda^{0}-1\right)\left(\Delta b_{1}+\Delta b_{2}\right)}{6}$ and $\delta>\left(2 \lambda^{0}-1\right)\left(\frac{2 \Delta b_{1}-\Delta b_{2}}{3}\right)$. To prove that prices are positive, it is enough to show that

$$
\left(2 \lambda^{\rho}-1\right)\left(\frac{\left(2 \Delta b_{1}-\Delta b_{2}\right)}{3}\right)-\frac{\left(2 \lambda^{0}-1\right)\left(\Delta b_{1}+\Delta b_{2}\right)}{6}>0 .
$$

This boils down to

$$
\frac{3 \Delta b_{1}-3 \Delta b_{2}}{6}>0
$$

which is always true.

Similarly, we can prove that prices are positive when $\rho=1$ and when $\rho=2$. 
Proof of Proposition 6. We need to show that $U_{t}^{0}<\lambda^{0} U_{t}^{1}+\left(1-\lambda^{0}\right) U_{t}^{2}$. First, to obtain the expected utility of a randomly selected type $t$ consumer in ranking situation 0 , we plug the equilibrium prices $f_{e}^{\rho, *}$ and $f_{c}^{\rho, *}$ (from Proposition 5) in (4). This gives:

$$
\begin{aligned}
U_{t}^{0}= & \frac{\left.\lambda^{0} b_{t}^{l}+\left(1-\lambda^{0}\right) b_{t}^{h}-\delta+\frac{\left(2 \lambda^{0}-1\right)\left(\Delta b_{1}+\Delta b_{2}\right)}{6}\right)}{2 \delta}\left(\frac{\left(2 \lambda^{0}-1\right)\left(\Delta b_{1}+\Delta b_{2}\right)}{3}-\Delta b_{t}\left(2 \lambda^{0}-1\right)+\delta\right) \\
& +\frac{\left.\lambda^{0} b_{t}^{h}+\left(1-\lambda^{0}\right) b_{t}^{l}-\delta-\frac{\left(2 \lambda^{0}-1\right)\left(\Delta b_{1}+\Delta b_{2}\right)}{6}\right)}{2 \delta}\left(\delta-\frac{\left(2 \lambda^{0}-1\right)\left(\Delta b_{1}+\Delta b_{2}\right)}{3}+\Delta b_{t}\left(2 \lambda^{0}-1\right)\right) \\
& +\frac{1}{2 \delta}\left(\frac{\delta^{2}}{2}-\frac{\left(\frac{\left(2 \lambda^{0}-1\right)\left(\Delta b_{1}+\Delta b_{2}\right)}{3}-\Delta b_{t}\left(2 \lambda^{0}-1\right)\right)^{2}}{2}\right)
\end{aligned}
$$

Second, we compute $\lambda^{0} U_{t}^{1}+\left(1-\lambda^{0}\right) U_{t}^{2}$ similarly. After some simple algebraic manipulations, we obtain:

$$
\begin{aligned}
\lambda^{0} U_{t}^{1}+\left(1-\lambda^{0}\right) U_{t}^{2}= & \frac{b_{t}^{l}-\delta+\frac{\left(\Delta b_{1}+\Delta b_{2}\right)}{6}\left(\delta+\frac{\left(\Delta b_{1}+\Delta b_{2}\right)}{3}-\Delta b_{t}\right)}{2 \delta}\left(\delta+\Delta b_{t}-\frac{\left(\Delta b_{1}+\Delta b_{2}\right)}{3}\right) \\
& \left.+\frac{b_{t}^{h}-\delta-\frac{\left(\Delta b_{1}+\Delta b_{2}\right)}{6}}{2 \delta}\left(1-\lambda^{0}\right) \frac{\left(\Delta b_{t}-\frac{\left(\Delta b_{1}+\Delta b_{2}\right)}{3}\right)^{2}}{2}\right) \\
& +\frac{1}{2 \delta}\left(\frac{\delta^{2}}{2}-\lambda^{0} \frac{\left(\frac{\left(\Delta b_{1}+\Delta b_{2}\right)}{3}-\Delta b_{t}\right)^{2}}{2}-(1)\right.
\end{aligned}
$$

Finally, combining (12) and (13), we can show (after some simple but tedious algebraic manipulations) that the condition $\lambda^{0} U_{t}^{1}+\left(1-\lambda^{0}\right) U_{t}^{2}>U_{t}^{0}$ boils down to

$$
0<2 \lambda^{0}\left(1-\lambda^{0}\right)\left(\frac{\Delta b_{1}+\Delta b_{2}}{3}-\Delta b_{t}\right) .
$$

Given that $\lambda^{0} \in(0,1)$ and $\left(\frac{\Delta b_{1}+\Delta b_{2}}{3}-\Delta b_{t}\right)^{2}>0 \forall t$ (except if $\Delta b_{1}=2 \Delta b_{2}$, which is non-generic) this is always satisfied.

Proof of Proposition 7. Consider the parameter values $\delta=0.455, b_{1}^{l}=b_{2}^{l}=1, b_{1}^{h}=2.1, b_{2}^{h}=1.5$, and $\lambda^{0}=0.9$. For these values of the parameters, we have that $\frac{\psi^{1}}{3}-\Delta b_{1}=-0.567<-\delta=-0.455$, $\frac{\psi^{2}}{3}+\Delta b_{1}=0.567>\delta=0.455$, and $\frac{\psi^{\rho}}{3}-\Delta b_{t}\left(2 \lambda^{\rho}-1\right) \in(-\delta, \delta)$ in all other cases. We thus have that the equilibrium prices are given by $(10),(11),(18),(19),(24)$ and (25):

$$
\begin{aligned}
& f_{e}^{0}=0.6683, f_{e}^{1}=1.2283, f_{e}^{2}=0.5917 \\
& f_{c}^{0}=0.2417, f_{c}^{1}=0.5917, f_{c}^{2}=1.2283 .
\end{aligned}
$$

In equilibrium, the demand for good $e$ under the different ranking situation is:

$$
d_{e}^{0}=1.4689, d_{e}^{1}=1.3498, d_{e}^{2}=0.6502 .
$$


The demand for good $c$ under the different ranking situation is:

$$
d_{c}^{0}=0.5311, d_{c}^{1}=0.6502, d_{c}^{2}=1.3498
$$

It remains to check that (i) $U_{t}^{1}<U_{t}^{0}$, and (ii) $U_{t}^{2}<U_{t}^{0}$ for all consumers:

$$
\begin{aligned}
U_{1}^{0}=1.3217 ; & U_{2}^{0}=1.1473 ; \\
U_{1}^{1}=0.8717 ; & U_{2}^{1}=0.3819 ; \\
U_{1}^{2}=0.8717 ; & U_{2}^{2}=0.464 .
\end{aligned}
$$

So ex post both types of consumers are better off without the ranking. Since all inequalities are strict and the equilibrium expected utilities are continuous in the parameters, this holds for an open set of parameters. And since ex post dominance implies ex ante dominance, the absence of the ranking also ex ante dominates its presence for an open set of parameters.

\section{Appendix A3: Non-Heterogeneous Demand}

\section{Case (A)}

As we will show below, in equilibrium, all type 1 consumers (no matter the $y_{1, i}$ ) request good $e$ when $\rho=1$ if $\frac{\psi^{1}}{3}-\Delta b_{1}\left(2 \lambda^{1}-1\right)<-\delta$. This implies that $1-F\left(\Delta f^{1}-\Delta b_{1}\right)=1$. Therefore, for the confirmative ranking $\rho=1$, the demand for $\operatorname{good} e$ is

$$
d_{e}\left(f_{e}^{1}, f_{c}^{1}\right)=\frac{3}{2}-\frac{\Delta f^{1}}{2 \delta}+\frac{\Delta b_{2}}{2 \delta}
$$

whereas the demand for good $c$ is

$$
d_{c}\left(f_{e}^{1}, f_{c}^{1}\right)=\frac{1}{2}+\frac{\Delta f^{1}}{2 \delta}-\frac{\Delta b_{2}}{2 \delta}
$$

For other ranking situations, i.e. $\rho=0,2$, the demand is given by (6) and (7).

Using (14) and (15), we find the best responses when $\rho=1$ : for firm $e$

$$
f_{e}^{1}\left(f_{c}^{1}\right)=\frac{3 \delta}{2}+\frac{f_{c}^{1}}{2}+\frac{\Delta b_{2}}{2},
$$

and for firm $c$

$$
f_{c}^{1}\left(f_{e}^{1}\right)=\frac{g_{c}}{2}+\frac{f_{e}^{1}}{2}-\frac{\Delta b_{2}}{2} .
$$

For other ranking situations, i.e. $\rho \neq 1$, the best response functions are given by (8) and (9)

To determine equilibrium prices, there are two cases to consider. First, the prices $\left(f_{e}^{1, *}, f_{c}^{1, *}\right)$ that we get by using (16) and (17) are such that $f^{1, *}-\Delta b_{1}<-\delta$, i.e. all type 1 consumers request good $e$ when the ranking is confirmative. Second, the prices $\left(f_{e}^{1, *}, f_{c}^{1, *}\right)$ that we get by using (16) and (17) are 
such that $f^{1, *}-\Delta b_{1} \in(-\delta, \delta)$, i.e. type 1 consumers request both types of goods when the ranking is confirmative. Since Proposition 7 is based on the first case, we do not investigate the second one any further. ${ }^{11}$

In the first case, the demand for goods $e$ and $c$ are given by (14) and (15), respectively. Therefore, equilibrium prices are:

$$
\begin{aligned}
f_{e}^{1, *} & =\frac{7}{3} \delta+\frac{\Delta b_{2}}{3}, \\
f_{c}^{1, *} & =\frac{5}{3} \delta-\frac{\Delta b_{2}}{3} .
\end{aligned}
$$

We find those using (16) and (17).

For the ranking situation $\rho=1$, we can also compute the expected utility of a randomly selected type $t$ consumer given the equilibrium prices $\left(f_{e}^{1, *}, f_{c}^{1, *}\right)$ :

$$
\begin{aligned}
U_{t}^{1}= & \underbrace{\int_{-\delta}^{\Delta f^{1, *}-\Delta b_{t}\left(2 \lambda^{1}-1\right)}\left(L_{t}^{1}-f_{c}^{1, *}\right) \frac{1}{2 \delta} d y_{t, i}}_{=0 \text { since } \Delta f^{1, *}-\Delta b_{t}\left(2 \lambda^{1}-1\right)<-\delta} \\
& +\int_{\Delta f^{1, *}-\Delta b_{t}\left(2 \lambda^{1}-1\right)}^{\delta}\left(H_{t}^{1}+y_{1, i}-f_{e}^{1, *}\right) \frac{1}{2 \delta} d y_{t, i} .
\end{aligned}
$$

This boils down to

$$
U_{t}^{1}=\int_{-\delta}^{\delta}\left(H_{t}^{1}+y_{t, i}-f_{e}^{1, *}\right) \frac{1}{2 \delta} d y_{t, i}=H_{t}^{1}-f_{e}^{1, *} .
$$

For $\rho=0$ and $\rho=2$ the results are the same as those described in section 4.1.1. Equilibrium prices are such that all type 1 consumers request good $e$ when the ranking is confirmative.

\section{Case (B)}

As we will show below, in equilibrium $\frac{\psi 2}{3}+\Delta b_{1}>\delta$, i.e. all type 1 consumers (no matter the $y_{i}$ ) request good $c$ when $\rho=2$. This implies that $F\left(\Delta f^{2}+\Delta b_{1}\right)=1$. Therefore, for the surprise ranking $\rho=2$, the demand for good $e$ is:

$$
d_{e}\left(f_{e}^{2}, f_{c}^{2}\right)=\frac{1}{2}-\frac{\Delta f^{2}}{2 \delta}-\frac{\Delta b_{2}}{2 \delta}
$$

The demand for good $c$ is

$$
d_{c}\left(f_{e}^{2}, f_{c}^{2}\right)=\frac{3}{2}+\frac{\Delta f^{2}}{2 \delta}+\frac{\Delta b_{2}}{2 \delta} .
$$

Using (20) and (21), we find the best responses when $\rho=2$ : for firm $e$

$$
f_{e}^{2}\left(f_{c}^{2}\right)=\frac{\delta}{2}+\frac{f_{c}^{2}}{2}-\frac{\Delta b_{2}}{2}
$$

and for firm $c$

$$
f_{c}^{2}\left(f_{e}^{2}\right)=\frac{3 \delta}{2}+\frac{f_{e}^{2}}{2}+\frac{\Delta b_{2}}{2} .
$$

\footnotetext{
${ }^{11}$ The analysis of the second case is available upon request.
} 
For equilibrium prices, there are two cases to consider. First, the prices $\left(f_{e}^{2, *}, f_{c}^{2, *}\right)$ that we get by using (22) and (23) are such that $\Delta f^{2, *}+\Delta b_{1}>\delta$, i.e. all type 1 consumers request good $c$ when the ranking is surprising. Second, the prices $\left(f_{e}^{2, *}, f_{c}^{2, *}\right)$ that we get by using (22) and (23) are such that $\Delta f^{2, *}+\Delta b_{1} \in(-\delta, \delta)$, i.e. type 1 consumers request both types of goods when the ranking is surprising. We only detail the first case because it is used in the welfare analysis (Proposition 7).

In the first case, demand for goods $e$ and $c$ are given by (20) and (21) respectively. Therefore, the equilibrium prices are:

$$
\begin{aligned}
f_{e}^{2, * *} & =\frac{5}{3} \delta-\frac{\Delta b_{2}}{3}, \\
f_{c}^{2, * *} & =\frac{7}{3} \delta+\frac{\Delta b_{2}}{3} .
\end{aligned}
$$

We find those using (22) and (23).

For the ranking situation $\rho=2$, we can also compute the expected utility of a randomly selected type $t$ consumer given the equilibrium prices $\left(f_{e}^{2, * *}, f_{c}^{2, * *}\right)$ :

$$
\begin{aligned}
U_{t}^{2} & =\int_{-\delta}^{\delta}\left(L_{t}^{2}-f_{c}^{2, * *}\right) \frac{1}{2 \delta} d y_{t, i} \\
& =L_{t}^{1}-f_{c}^{1, * *} .
\end{aligned}
$$

